\title{
Corticotropin Releasing Factor promotes breast cancer cell motility and invasiveness
}

Ariadne Androulidaki ${ }^{1}$, Erini Dermitzaki ${ }^{1}$, Maria Venihaki ${ }^{1}$, Effie Karagianni ${ }^{1}$, Olga Rassouli ${ }^{1}$, Erini Andreakou${ }^{1}$, Christos Stournaras ${ }^{2}$, Andrew N Margioris*1 and Christos Tsatsanis*1

\author{
Address: ${ }^{1}$ Department of Clinical Chemistry, School of Medicine, University of Crete, Heraklion 71003, Crete, Greece and ${ }^{2}$ Department of \\ Biochemistry, School of Medicine, University of Crete, Heraklion 71003, Crete, Greece \\ Email: Ariadne Androulidaki - arandrou@med.uoc.gr; Erini Dermitzaki - renaderm@med.uoc.gr; Maria Venihaki - venihaki@med.uoc.gr; \\ Effie Karagianni - efi.karagianni@yahoo.gr; Olga Rassouli - orassouli@edu.med.uoc.gr; Erini Andreakou - eandreak@yahoo.gr; \\ Christos Stournaras - cstourn@med.uoc.gr; Andrew N Margioris* - andym@med.uoc.gr; Christos Tsatsanis* - tsatsani@med.uoc.gr \\ * Corresponding authors
}

Published: 2 June 2009

Molecular Cancer 2009, 8:30 doi:10.1186/1476-4598-8-30
Received: 30 January 2009

Accepted: 2 June 2009

This article is available from: http://www.molecular-cancer.com/content/8/I/30

(c) 2009 Androulidaki et al; licensee BioMed Central Ltd.

This is an Open Access article distributed under the terms of the Creative Commons Attribution License (http://creativecommons.org/licenses/by/2.0), which permits unrestricted use, distribution, and reproduction in any medium, provided the original work is properly cited.

\begin{abstract}
Introduction: Cancer cells secrete bioactive peptides that act in an autocrine or paracrine fashion affecting tumor growth and metastasis. Corticotropin-releasing factor (CRF), a hypothalamic neuropeptide that controls the response to stress, has been detected in breast cancer tissues and cell lines. CRF can affect breast cancer cells in an autocrine or paracrine manner via its production from innervating sympathetic neurons or immune cells.
\end{abstract}

Methods: In the present study we report our findings regarding the impact of CRF on breast cancer cell motility and invasiveness. For this purpose we used the MCF7 breast cancer cell line and evaluated the effect of CRF on motility and invasiveness using the wound-healing and boydenchamber assays. In addition, we measured the effect of CRF on molecules that mediate motility by western blot, immunofluorescence, ELISA and RT-PCR.

Results: Our findings show that: I. CRF transiently inhibited the apoptosis of MCF7 cells. 2. CRF enhanced MCF7 cell motility in a wound healing assay and their invasiveness through extracellular matrix. 3. CRF increased actin polymerization, phosphorylation of Focal Adhesion Kinase (FAK), providing a potential mechanism for the observed induction of MCF7 motility. 4. CRF induced the expression of Cox-I but not Cox-2 in MCF7 cells as well as the production of prostaglandins, factors known to promote invasiveness and metastasis.

Conclusion: Overall, our data suggest that CRF stimulates cell motility and invasiveness of MCF7 cells most probably via induction of FAK phosphorylation and actin filament reorganization and production of prostaglandins via Coxl. Based on these findings we postulate that the stress neuropeptide CRF present in the vicinity of tumors (either produced locally by the tumor cells themselves or by nearby normal cells or secreted from the innervations of surrounding tissues) may play an important role on breast tumor growth and metastatic capacity, providing a potential link between stress and tumor progression. 


\section{Introduction}

Neuropeptides and their receptors are present in the tumor microenvironment affecting cancer progression [14]. Neuropeptides are known to be produced either from the tumor cells themselves or by nearby located nontumor cells, such as stroma, immune cells or by innervating autonomic neurons. Corticotropin-releasing factor (CRF) is the major hypothalamic mediator of the response to stress. CRF is also a well-known homeostatic paracrine modulator in the periphery. CRF peptides and their receptors are also expressed in several types of tumors [5-8].

The neuropeptide CRF and its family members Urocortin (UCN)1, UCN2 and UCN3 act via two receptors, CRF1 and CRF2, subtypes of which are differentially expressed in the central nervous system (CNS) and a multitude of peripheral tissues $[9,10]$. Apart of the well-characterized role of CRF in the homeostatic response to stress, several actions in peripheral tissues have also been described. The CRF system has been implicated in the physiology of the cardiovascular, reproductive and gastrointestinal systems [11-13]. Moreover, CRF peptides and their receptors are also present in the immune system and possess immunomodulatory properties [14-18].

Peptides of the CRF family and their receptors have been detected in various tumors. Several neuroendocrine tumor cell lines such as the PC12 pheochromocytoma, Y79 retinoblastoma, IMR-32 and SH-SY5Y neuroblastoma, AtT-20 pituitary carcinoma and NCI-H82 small cell lung cancer cell lines express CRF and the CRF1 receptor [19-22]. In addition, epithelial tumors and epithelial tumor cell lines express CRF receptors. CRF1 receptors have been detected in the MCF7 breast cancer cell line, while CRF immunoreactivity has been reported in surgical breast cancer specimen, suggesting a role for the CRF/CRFreceptor system in breast cancer [23]. CRF and its receptors are also expressed in human melanomas and in melanoma cell lines $[6,7]$. It should be noted here that CRF is constantly present in the microenvironment of tumors produced by nearby cells including endothelial cells [24] and immune cells [14] and by the local neuronal innervations [25].

A number of reports support both a tumor-promoting and a tumor-inhibitory effect of CRF peptides. Thus, in the endometrial adenocarcinoma cell line Ishikawa UCN and CRF inhibit cell proliferation via CRF1 [5]. UCN was also shown to inhibit the proliferation of melanoma cells both in vitro and in vivo, through CRF1 [26]. In the human breast cancer cell line MCF7, CRF inhibits estrogeninduced proliferation via CRF1 [23]. Moreover, CRF and CRF related peptides, sauvagine and $\mathrm{UCN}$, inhibit the proliferation of human HaCaT keratinocytes via CRF1 [27].
In addition, CRF has been found to induce the expression of Fas ligand and apoptosis in the rat PC12 pheochromocytoma cell line also via CRF1 [28]. In contrast, in the Y79 retinoblastoma cell line CRF suppresses apoptosis via downregulation of pro-caspase 3 cleavage and activation [29]. It should be mentioned here that the tumor-promoting properties for CRF can be supported by the fact that CRF induces Fas ligand production in ovarian cancers, an effect resulting in cytotoxic T-cell apoptosis and local immunosuppression [8]. Interestingly, ligands of the other CRF receptor, the CRF2, have been found to suppress tumor growth while the expression of the CRF2-specific endogenous ligand UCN2 in tumors results in reduced angiogenesis and suppression of tumor growth [30].

Even though expression of CRF and its receptors has been described in different types of cancer cells, the role of these peptides in tumor growth and metastasis has not been elucidated. The aim of this work was to study the role of CRF in breast cancer cell homeostasis, motility and invasiveness. For this purpose we utilized the MCF7 breast cancer cell line and found that while CRF affected apoptosis it also promoted cell motility and invasiveness, supporting a tumor-promoting role for CRF and CRF1 signals.

\section{Methods \\ Cell culture}

The human breast cancer cell line MCF7 was cultured in Dulbecco's Modified Eagle Medium (DMEM) supplemented with $10 \%$ fetal calf serum (FCS) and $1 \%$ penicillin/streptomycin (all purchased from Invitrogen, UK), at $37^{\circ} \mathrm{C}$ in a $5 \% \mathrm{CO} 2$ humidified atmosphere. Cells were plated at a concentration of $2 \times 10^{5} \mathrm{cells} / \mathrm{ml}$ until next day when they had reached at approximately $80 \%$ confluence. The medium was replaced with serum-free one and cells where stimulated with CRF (Tocris, UK) at a concentration of $10^{-8} \mathrm{M}$ for different time points. Control cells were treated with the CRF diluent, being $0.1 \%$ acetic acid. When antagonists or inhibitors were used, antagonists were administered one hour prior to stimulation with the peptide; a-helical CRF (Sigma, USA) and astressin-2B (kindly provided by Dr. J. Spiess), antagonists of CRF1 and CRF2 respectively, were used at a concentration of $10^{-}$ ${ }^{6} \mathrm{M}$.

\section{RNA isolation and Reverse Transcription-PCR}

Total cellular RNA was isolated using Trizol reagent (Invitrogen, UK). Following reverse transcription (Thermoscript RT, Invitrogen, UK), $1 \mu \mathrm{l}$ of the cDNA product was amplified by PCR (Platinum Taq polymerase, Invitrogen, UK). The primer sets, previously reported to detect the respective CRF receptors in human brain specimen [31], were: CRF1a (272 bp): sense 5'-GGCAGCTAGTGGTTCG- 
GCC-3' and antisense 5'-TCGCAGGCACCGGATGCTC-3'; CRF1b: sense 5'-GGCCAGGCTGCACCCATTG-3'; antisense 5'-TCGCAGGCACCGGATGCTC-3'; CRF2a: sense 5'ATGGACGCGGCACTGCTCCA-3'; antisense 5'-CACGGCCTCTCCACGAGGG-3'. For CRF2b (342 bp) sense 5'GGGGCTGGCCAGGGTGTGA-3' and antisense 5'-CACGGCCTCTCCACGAGGG-3'. CRF2c (300 bp): sense 5'CTGTGCTCAAGCAATCTGCC-3' and antisense 5'-CACGGCCTCTCCACGAGGG-3'. Beta-Actin (214 bp): sense 5'CCGGCCAGCCAGGTCCAGA-3' and antisense 5'-CAAGGCCAACCGCGAGAAGATG-3'. Products were amplified using the following PCR conditions: denaturation at $95^{\circ} \mathrm{C}$ for 45 seconds, annealing at $60^{\circ} \mathrm{C}$ for 45 seconds, extension at $72^{\circ} \mathrm{C}$ for 45 seconds, for a total of 40 cycles. A sample where no-reverse transcriptase was added during reverse transcription of the RNA (no RT) and another where water was added instead of cDNA, were used as controls. $12 \mu \mathrm{l}$ of the amplified products were separated on a $2.5 \%$ agarose gel and visualized by ethidium bromide staining using the BioRad Molecular Analyst System [32].

\section{Quantitative measurement of apoptosis}

The APOPercentage apoptosis assay (Biocolor Ltd., Belfast, UK) was used to quantify apoptosis, according to manufacturer's instructions. Briefly, cells were plated in flat bottom 96-well plates at a concentration of 15,000 cells/well and the next day medium was replaced by medium free of serum containing CRF at a concentration of $10^{-8} \mathrm{M}$, for different time points. One hour before the end of the experiment, $5 \mu \mathrm{l}$ of the APOPercentage dye was added to each well for one hour. Cells were then washed with PBS and lysed in the Dye Release Reagent. The APOPercentage Apoptosis Assay's dye stained red the apoptotic cells undergoing the membrane flip-flop event, when phosphatidylserine is translocated to the outer leaflet. Apoptosis was quantified after cell lysis by measuring the dye incorporated in apoptotic cells at $550 \mathrm{~nm}$ (reference filter $620 \mathrm{~m}$ ) using an Elisa reader (Biorad, UK).

\section{Quantitative measurement of cell growth}

Cell growth was measured using the yellow tetrazolium MTT assay (Sigma, USA). The yellow tetrazolium MTT is reduced by metabolically active cells, in part by the action of dehydrogenases. Briefly, 15,000 cells were plated in 96 well plates and treated with CRF At the end of the incubation period MTT was added at a concentration of $0.5 \mathrm{mg} /$ $\mathrm{ml}$ and incubated for 3 hours. Cells were then lysed by adding $0.04 \mathrm{~N} \mathrm{HCl}$ in isopropanol and absorbance was measured at $620 \mathrm{~nm}$ in an ELISA plate reader (Biorad, UK).

\section{Wound healing assay}

Cells were cultured in $60 \mathrm{~mm}$ plates until the surface was completely covered. A small area was then disrupted and a group of cells was destroyed or displaced by scratching a line through the layer with a tip [33]. The culture medium was replaced with serum free medium and cells were stimulated with $10^{-8} \mathrm{M}$ CRF. The open gap was then inspected microscopically (Leica, Germany) over time as the cells moved in and filled the damaged area. Images were captured at the beginning and at regular time points during cell migration and the cell migration was quantified by measuring the distance with the program Image J http:// rsbweb.nih.gov/ij/ between two certain points on either side of the gap. For proper statistical evaluation, at least three measurements at different points were performed at each image.

\section{Cell Invasion Assay}

The assay was performed in a 96 well invasion plate based on the Boyden chamber principle. The bottom of each well contained an $8 \mu \mathrm{m}$ pore size polycarbonate membrane coated with a thin layer of Extracellular Matrix (ECM) through which invasive cells migrate to the bottom of the membrane. Invaded cells were dissociated, lysed and quantified by fluorometric analysis using SYBR green, according to the manufacturer's instructions (Chemicon, USA).

\section{Evaluation of actin reorganization by Confocal Laser Scanning Microscopy}

Cells were cultured in 8-well chambers slides (50,000 cells per well). The next day the culture medium was replaced with serum free medium and cells were stimulated with $10^{-8} \mathrm{M}$ CRF for 1,3 and 6 hours. At the end of each experiment, cells were harvested, transferred to tubes, washed with PBS and permeabilized by exposure to $3.7 \%$ formaldehyde for 10 minutes. Cells were then incubated with acetone for 4 minutes at room temperature, washed with PBS and incubated with $1.5 \%$ FCS. Finally, rhodaminephalloidin was added to the cells at 1:100 dilution in PBS/ FCS $1.5 \%$ for $30 \mathrm{~min}$ in the dark. Subsequently, cells were washed with PBS, analyzed with a confocal laser-scanning module (Leica Lasertechnik, Heidelberg Germany) and images were assessed with the respective software.

\section{Measurement of monomeric (G) and polymeric (F) actin by Triton X-I00 fractionation}

The Triton X-100 soluble G-actin and insoluble F-actincontaining fractions of cells exposed to CRF at $10^{-8} \mathrm{M}$ in serum free medium for 3 and 6 hours were prepared as previously described [34]. The quantification of actin was performed by reference to a standard curve, prepared from muscle actin [34]. The G- and total actin contents were related to the total protein content. Protein concentrations were measured with a commercially available kit (Bio-Rad, UK). A decrease of the triton-soluble (G) to total actin ratio [triton-insoluble $(F)+$ triton-soluble $(G)$ ] is indicative of actin polymerization. 


\section{Measurment of FAK phosphorylation (Confocal Laser Scanning Microscopy)}

Cells were cultured in 8-well chambers slides (50,000 cells per well). The next day the culture medium was replaced with serum free medium and cells were stimulated with $10^{-8} \mathrm{M}$ CRF for 3 hours. Cells were harvested, washed with PBS containing NaF and PMSF and incubated with PFA $4 \%$ for $10 \mathrm{~min}$. Cells were then washed with PBS and $0.1 \%$ Triton X-100 was added for 15 minutes. Then, cells were incubated overnight with a monoclonal antibody against the phosphorylated form of FAK (Cell signaling, USA). Finally, cells were washed with PBS, stained with secondary anti-mouse Ig FITC-conjugated antibody raised in goat, for 1 hour and photographed with a Confocal Laser Scanning Microscope.

\section{Measurement of total prostaglandin production}

$2 \times 10^{5}$ cells were plated in 24 well plates and stimulated with CRF $10^{-8}$ for different time points. The supernatants of the cells were collected and stored at $-80^{\circ} \mathrm{C}$ until analyzed. The production of total prostaglandins was measured by the Prostaglandin Screening EIA Kit (Cayman, USA) according to the manufacturer's instructions. The assay is based on the competition between PGs and a PGacetylcholinesterase conjugate for a limited amount of PG antiserum.

\section{Western blotting analysis}

Western blot analysis of proteins for the detection of tubulin (Chemicon, USA), Cox-1 (Chemicon, USA) and Cox2 (Santa Cruz, California, USA) was performed as previously described [28]. Briefly, protein content in the lysates was measured by Bradford Assay. SDS-PAGE sample loading buffer was added in $10 \mu \mathrm{g}$ of protein from each lysate and electrophoresed through a $12 \%$ SDS polyacrylamide gel. Protein was transferred to nitrocellulose membranes, using an LKB electroblot transfer system (LKB, Bromma, Sweden). To detect protein levels, membranes were incubated with the appropriate antibodies and then exposed to Kodak X-omat AR films. A PC-based Image Analysis was used to quantify the intensity of each band (Image Analysis INC., Ontario, Canada).

\section{Statistical analysis}

All values were expressed as the average \pm Standard Error of data obtained from at least three independent experiments. Comparison between groups was made using the ANOVA test (single factor) and $\mathrm{p}<0.05$ was the significance level.

\section{Results}

I. Expression of CRF receptor subtypes in MCF7 cells

To confirm that any biological effect of CRF in MCF7 cells occurred via the characterized CRF receptors we investigated the expression of different CRF receptor subtypes.
Expression of CRF1 has been previously reported in MCF7 cells [23]. RNA from MCF7 cells was analyzed for the expression of CRF1a, CRF1b, CRF2a and CRF2c receptor subtypes by RT-PCR. Among these four subtypes, CRF1a mRNA was expressed in high levels while CRF2c mRNA was present at very low levels (Figure 1). The mRNAs of CRF1b, CRF2a were detected in human hippocampus but were not detected in MCF7 cells (Figure 1).

\section{CRF affects apoptosis of MCF7 cells in a time dependent-manner}

Evasion of apoptosis is a hallmark of cancer cells and is frequently associated with proliferation and invasiveness [35-38]. It has been previously reported that CRF has antiproliferative effects on cancer cell lines such as Ishikawa endometrial carcinoma cells and in MCF7 stimulated by estrogens [5,23]. Herein we confirmed that CRF suppresses MCF7 cell proliferation (Figure 2A) and determined its effect on apoptosis by measuring the exposure of phosphatidyl-serine on the cell membrane. MCF7 were treated with CRF at a concentration of $10^{-8} \mathrm{M}$ for 24,48 , and 72 hours and apoptosis was quantified. Control cells were treated with vehicle ( $0.1 \%$ acetic acid). CRF stimulation significantly protected MCF7 cells from serum deprivation-induced apoptosis becoming evident 48 hours following stimulation (Figure 2B). At later time points apoptosis appeared increased, suggesting a biphasic effect of CRF on apoptosis.

\section{CRF promotes the motility of MCF7 cells}

Increase in cell motility has an impact on the metastatic potential of cancer cells. We, therefore, tested whether CRF could increase motility of MCF7 cells, a cell line with low metastatic potential. To this end we performed a wound healing assay in MCF7 cells, in which a line was formed by scratching the cell monolayer with a tip [33]. In this model the gap is mainly covered by cells that move to close it rather than cells that proliferate, at least at the early time points when cells do not have enough time to proliferate. At the 24 hour time point the result is a combination of proliferation and motility. The size of the gap was measured at different time points following stimulation using specialized software. Cells were treated with CRF at time 0 and were compared to vehicle only-treated cells at for the same period. Results are presented as \% of the distance that remained open at that particular time point (Figure 3 ). Hence, at 12 hours $75.08 \pm 1.57 \%$ of the initial gap was still open in control, vehicle treated cells, while $56.93 \pm 1.17 \%$ of the gap was still open in CRF-treated cells. At 24 hours $55.42 \pm 0.65 \%$ was still open in control cells while only $40.75 \pm 0.35 \%$ of the gap was still uncovered in CRF-treated cells, suggesting that CRF promoted their motility. Given the fact that CRF reduced cell proliferation and apoptosis was not evident at 24 hours following stimulation (Figure 2), the results suggest that CRF 


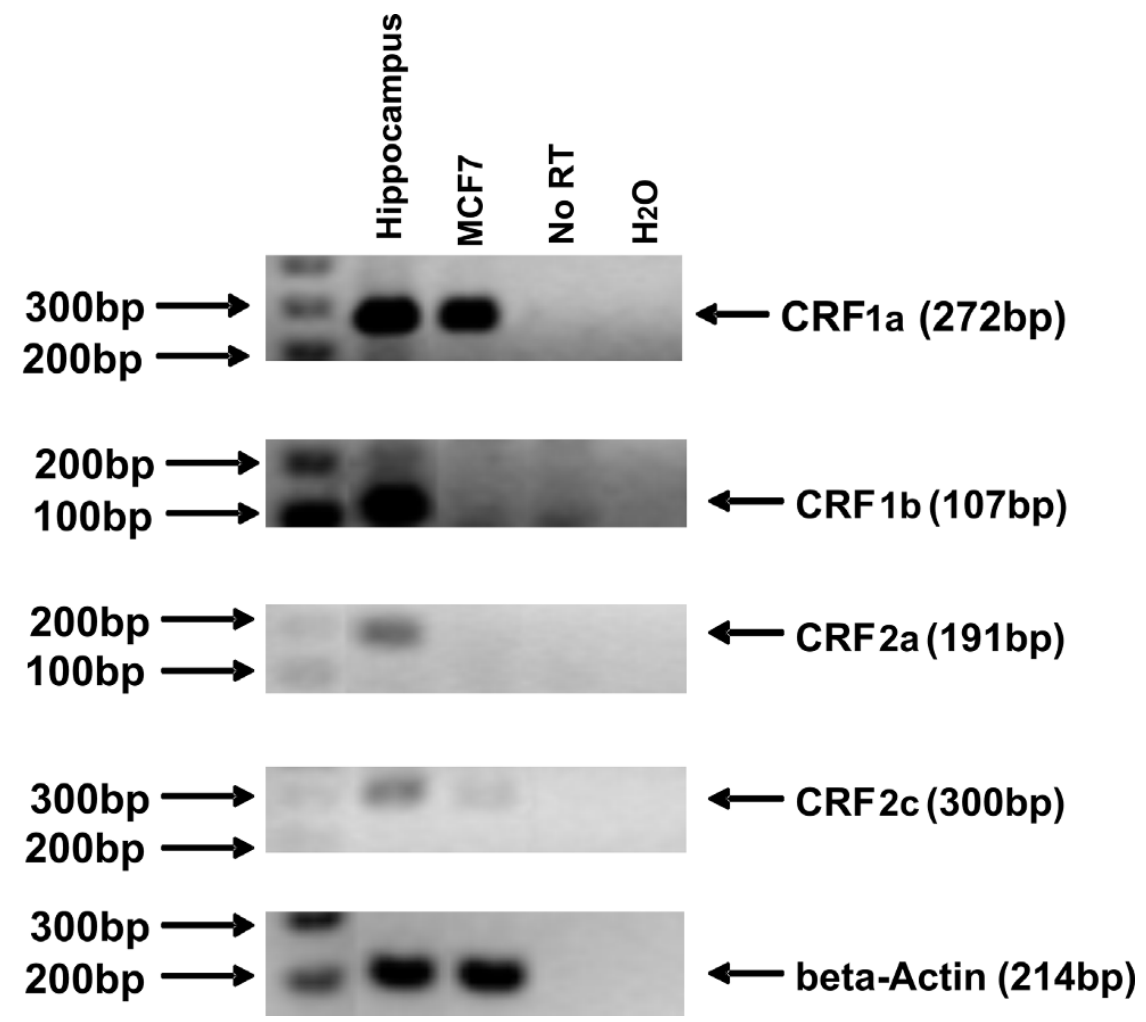

\section{Figure I}

CRF I a and CRF2c are expressed in MCF7 cells as detected by RT-PCR. Total RNA was isolated from MCF7 cells and the expression of CRF receptors subtypes CRFIa, CRFIb, CRF2a and CRF2c were detected by semi-quantitative RT-PCR. The levels of beta Actin were also measured as a normalization control. Results are representative of three independent experiments.

stimulated motility that resulted in faster closure of the gap. The histograms represent the average of four independent experiments.

\section{CRF induced MCF7 cell invasion through extracellular matrix}

Invasion through the extracellular matrix (ECM) is a prerequisite for tumor metastasis. Since we found that CRF increased cell motility we further investigated whether it promoted invasiveness through extracellular matrix. MCF7 cells were plated on an ECM layer on a Boyden Chamber in the presence or absence of CRF and migration of cells through ECM was evaluated. As shown in Figure 4, incubation of MCF7 with CRF augmented the invasion of the cells through ECM. Moreover, the CRF1 antagonist, ahelical CRF abrogated the effect of CRF, while the CRF2 antagonist asstressin-2B had no effect (Figure 4).

\section{CRF promoted actin cytoskeleton reorganization in MCF7 cells}

To determine the potential mechanism involved in CRFinduced motility and invasiveness we examined the effect of CRF on actin polymerization dynamics. Actin a major cytoskeletal component in eukaryotic cells occurs in two forms, the globular or G-actin, which polymerizes into the filamentous or F-actin. Filamentous actin is the major component of microfilaments, present in filipodia and lamellipodia, which are reported to facilitate cell migration [39]. In order to assess the role of CRF on cytoskeletal actin reorganization, we stained MCF7 cells stimulated with CRF or vehicle ( $0.1 \%$ acetic acid) for different time points with rhodamine-phalloidin that binds specifically to polymerized actin and visualized cells by confocal microscopy, evaluating actin filament structure and fluorescence intensity. As shown in Figure 5A, CRF induced alterations in actin cytoskeleton morphology, indicating changes in the polymerization dynamics of this protein. To quantify the extent of actin polymerization that occurred in the presence of CRF we analyzed the amount of monomeric $\mathrm{G}$ actin and compared it to the expression of total actin (monomeric $\mathrm{G}$ and polymeric $\mathrm{F}$ ) providing the ratio between the two forms as previously reported $[33,40,41]$. Three hours following CRF stimulation the G/ total actin ratio was significantly reduced, suggesting actin 
A.

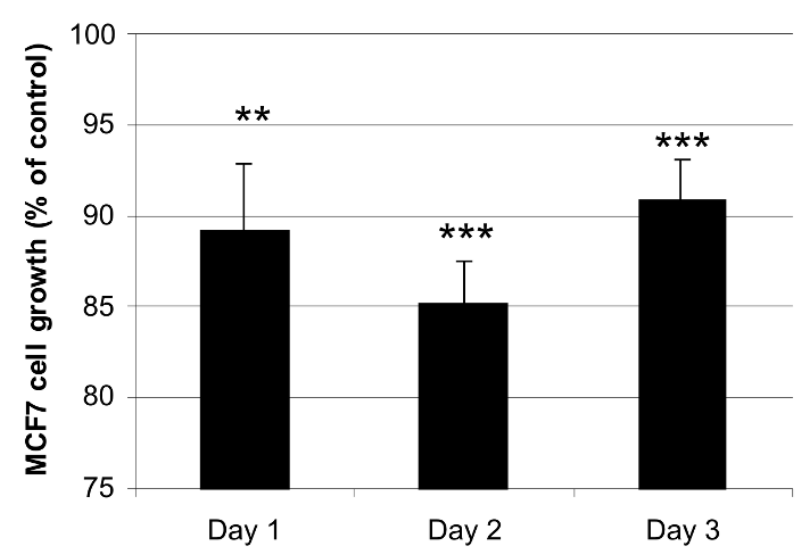

B.

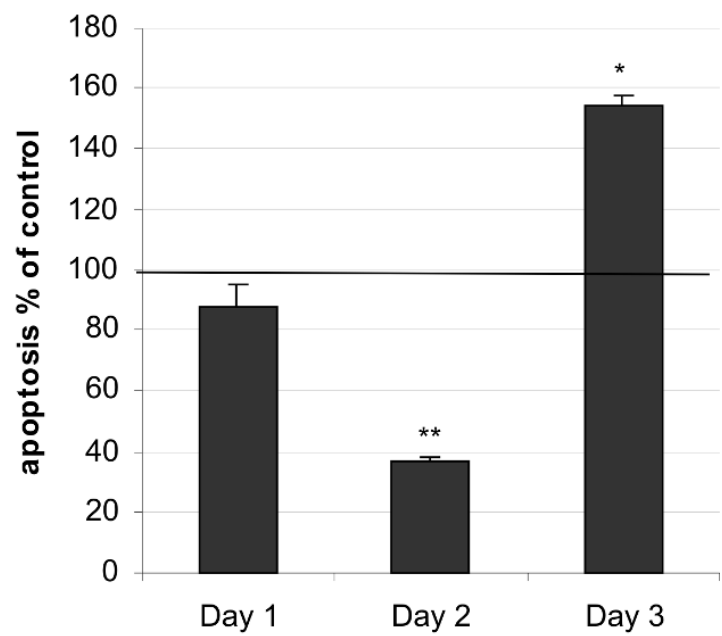

Figure 2

CRF affected proliferation and apoptosis of MCF7 cells in a time dependent manner. Cells were stimulated with I0-8 M CRF or vehicle (control) for 24,48 , and 72 hours, and cell growth was measured using the MTT assay (A); apoptosis was measured by the ApoPercentage Assay (B). CRF significantly suppressed proliferation at all time points tested and apoptosis 48 hours after CRF stimulation. Data are expressed as \% of control (unstimulated cells). Results represent the average of 4 independent experiments where each condition was assayed in triplicate. $*_{p}<0.05 ; *_{p}<0.01$ compared to control cells at the same time point.

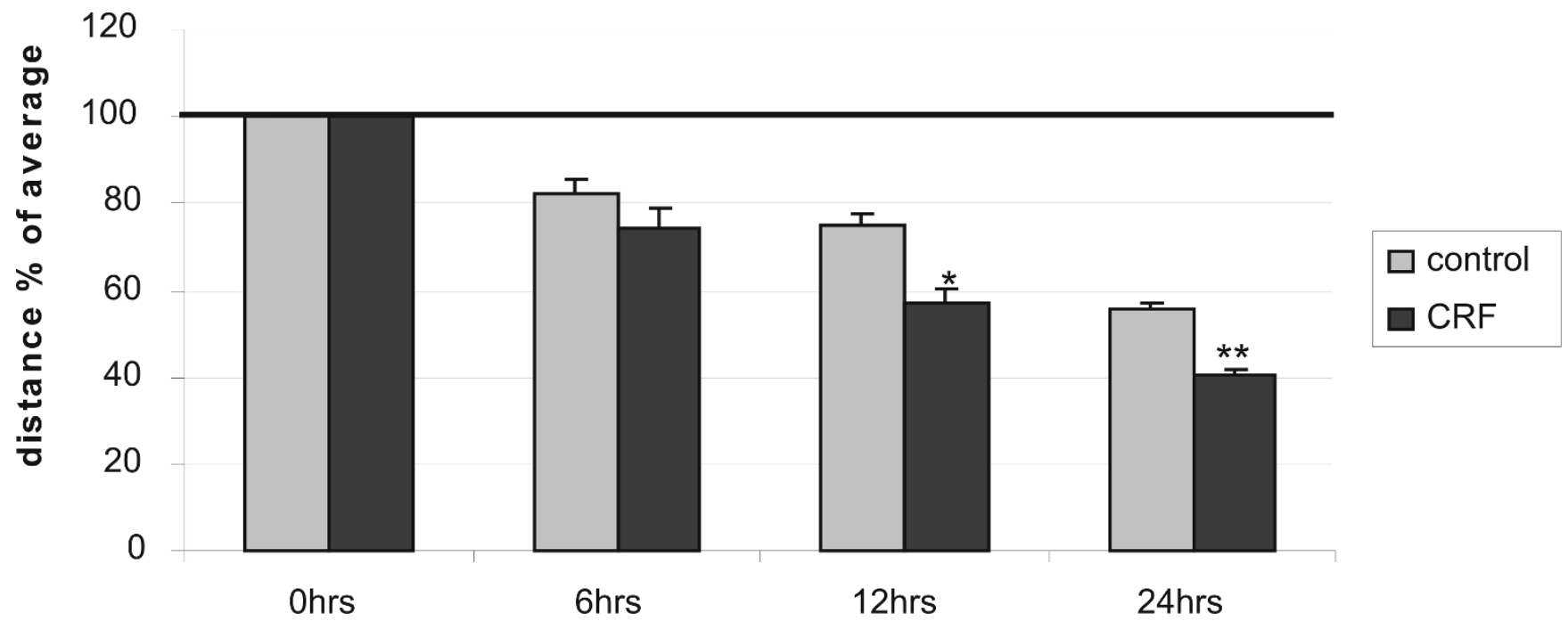

Figure 3

CRF induces the motility of MCF7 in a wound healing assay. MCF7 cells were stimulated with 10-8 M CRF or vehicle (control) and photographed at 0, 6, 12 and 24 hours after disruption of a small area of the cell layer. The remigration of the cells was quantified by measuring the distance at 3 at least different positions on each image with the program Image J, and expressed the distance as \% of the average. Results represent the average of three independent experiments. ${ }^{*} p<0.05 ; *^{*} p<$ 0.0 l compared to control cells at the same time point. 


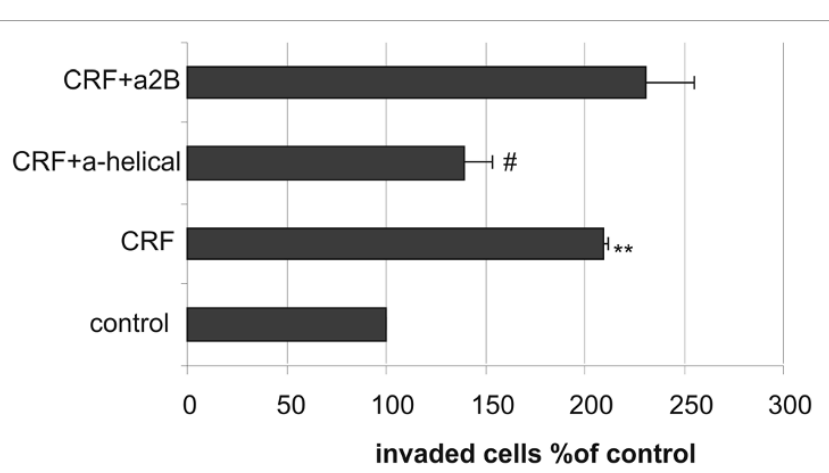

Figure 4

CRF enhances the invasion of MCF7 through ECM via CRF I. MCF7 cells were stimulated with 10-8 M CRF or vehicle (control) and the invasion assay was performed according to the manufacturer's instructions. CRF augmented the invasion of the cells through the ECM. Pretreatment with the CRFI antagonist (10-6 M) abrogated the effect of CRF. Results represent the average of two independent experiments where each condition was assayed in triplicate. ${ }^{* *} \mathrm{p}<$ 0.01 compared to untreated controls; \#p $<0.05$ compared to CRF-treated samples.

polymerization and formation of actin microfilaments (Figure 5B). Six hours later new monomeric actin was produced restoring the ratio of monomeric versus polymeric to the original state but with overall higher expression of actin, as indicated in Figure 5A.

FAK activation by phosphorylation is the first element, which may transmit extracellular signals to downstream signaling proteins, leading to actin reorganization [40,42$44]$ and is implicated in cell migration $[33,41]$. We, therefore, examined the effect of CRF on FAK phosphorylation in MCF7 cells. As shown in Figure 6, the phosphorylation of FAK was significantly increased in CRF treated MCF7 cells compared to vehicle-treated cells, indicating that it may also affect MCF7 cell invasiveness.

\section{CRF increases prostaglandin production in MCF7 cells via Cox-I}

Cyclooxygenases (Cox), the enzymes that convert arachidonic acid into prostaglandins, have been causally linked to breast cancer cell proliferation, motility and invasiveness [45-48], thus the effect of CRF in prostaglandin production and Cox expression was investigated. We measured total prostaglandin production in supernatants of MCF7 cells stimulated with CRF by ELISA and found that CRF induced prostaglandin production in MCF7 cells (Figure 7A). CRF did not induce PGE2 production in MCF7 cells as measured by ELISA (data not shown). Indeed, COX-2 was not induced by CRF in this cell type (Figure 7B). In contrast, CRF induced COX-1 expression in a time-dependent manner, suggesting that COX-1 mediates CRF-induced prostaglandin production (Figure 7C).

\section{Discussion}

Breast cancer growth is affected by several autocrine and paracrine factors that regulate tumor cell proliferation, apoptosis and metastatic potential. CRF is the major hypothalamic stress-induced neuropeptide but is also found in peripheral tissues. The aim of the study was to define the potential effect of CRF on breast cancer cell proliferation, apoptosis and metastatic potential.

We first investigated the expression of CRF receptors in MCF7 cells to confirm that the cells are responsive to CRF. In a previous report CRF1 receptor was detected in MCF7 cells [23]. In the present study we found that the CRF1a isoform was expressed in these cells and CRF2c was also present but at very low levels, indicating that the major mediator of CRF actions in MCF7 cells is CRF1 receptor. Indeed, inhibition of CRF2 receptors had no effect at least in the induction of cell invasion by CRF. These observations warrant further analysis of the CRF receptor system in primary breast cancer tissues that will support the significance of these receptors in breast cancer.

Earlier studies had shown that CRF suppressed breast cancer cell proliferation while it promoted proliferation in melanoma cells [6]. Our studies confirmed the suppressive effect of CRF on MCF7 proliferation. We further investigated the role of CRF on MCF7 cell apoptosis and found that CRF inhibited apoptosis. The effect of CRF on apoptosis varies depending on the cell type and the time detected. Thus, in PC12 rat pheochromocytoma cells CRF promoted apoptosis [28] while in neuroblastoma [29] and in melanoma cells it inhibited apoptosis [26]. An earlier study in MCF7 cells showed no effect of CRF on apoptosis using a less sensitive method, this of visualizing fragmented DNA [23]. Differences between cell types may be attributed to different factors that the cells may produce; i.e in Y79 neuroblastoma cells CRF inhibited caspase 3 activity [29], while PC12 cells undergo apoptosis in response to CRF due to production of FasL [28], which is not expressed in MCF7 cells.

The fact that CRF affected apoptosis and at the same time it inhibited cell proliferation may indicate changes in the cellular physiology that could contribute to a metastatic phenotype. Reduced cell proliferation, at least temporary, is required for cells to reorganize their cytoskeleton and promote motility. Indeed, CRF induced motility in MCF7 cells as demonstrated by a wound-healing assay. Cell motility is facilitated by cytoskeletal rearrangements that are characterized by actin polymerization. Our results indicated that CRF promoted polymerization of actin as 
A.
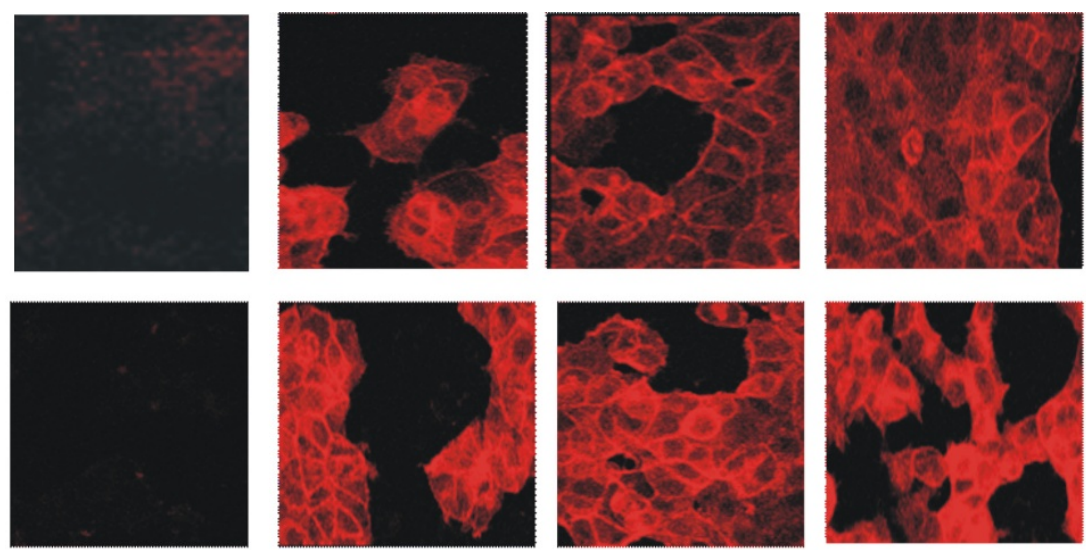

$1 \mathrm{hr}$

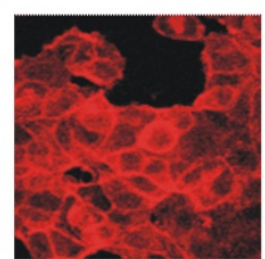

3hr

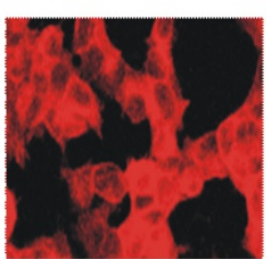

$6 \mathrm{hr}$

\section{control}

untreated

\section{CRF}

B.

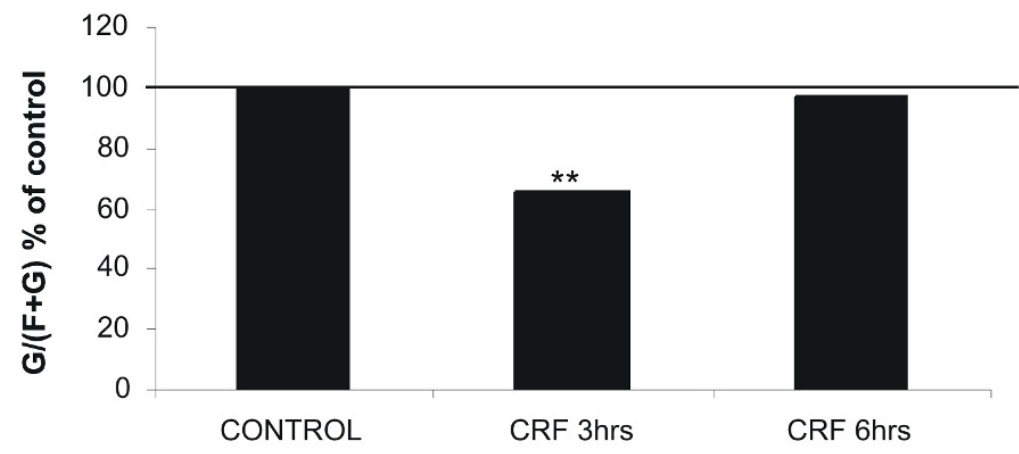

\section{Figure 5}

A. CRF affects actin cytoskeleton. MCF7 cells were plated in chamber-slides, stimulated with 10-8 M CRF or vehicle (control) for I, 3 and 6 hours and stained with rhodamine-phalloidine. Fluorescence was measured by confocal microscopy. Results are representative of three independent experiments. B. CRF induces actin polymerization. MCF7 cells were stimulated with CRF $\left(10^{-8} \mathrm{M}\right)$ or vehicle (control) for 3 and 6 hours. Cells were harvested and the two fractions, soluble and insoluble, containing the monomeric (globular) and the polymerized (filamentous) actin respectively were isolated and analyzed by western blotting using antibody against actin. The relative proportion of $\mathrm{F}$ - and $\mathrm{G}$-actin was determined by the concentration of monomeric $(\mathrm{G})$ and total $(F+G)$ actin and the result is presented as the $G /(F+G)$ ratio induced by $C R F$ compared to control; $p<0,0 I$. Results represent the average of five independent experiments.

determined by measuring the ratio of the monomeric versus the polymeric actin, as well as visualizing polymerized actin by immunofluorescence using confocal laser scanning microscopy. Increased actin polymerization is associated with dynamic changes in cytoskeletal structures that allow cells to migrate and metastasize [49]. Focal Adhesion Kinase is a cytoskeleton associated kinase that is activated by phosphorylation and mediates signals to promote cell adhesion and migration [50]. FAK also seems to play a role in tumor development since it has been shown that primary human cancer cells or cell lines overexpress the protein as well as its phosphorylated form [51,52]. In particular, FAK was found to overexpressed and to be highly activated in tumorigenic DU145 and PC-3 cells as well as in prostate cancer tissues from patients with metas- tasis $[52,53]$ whereas in $\mathrm{LNCaP}$ cells that have a lower tumorigenic ability FAK was observed to be much lower [44,52]. We found that CRF promoted phosphorylation of FAK providing a potential mechanism for the actin reorganization and increased migration observed in response to CRF. It is, thus, likely that CRF initiates signals that promote cytoskeletal changes resulting in cell adhesion and migration by activating pathways that involve FAK phosphorylation.

The metastatic process requires that cells do not only have increased motility but they should also obtain the capacity to migrate through the ECM. For this purpose we examined the effect of CRF to promote invasion through ECM in MCF7 cells that have low metastatic potential. 


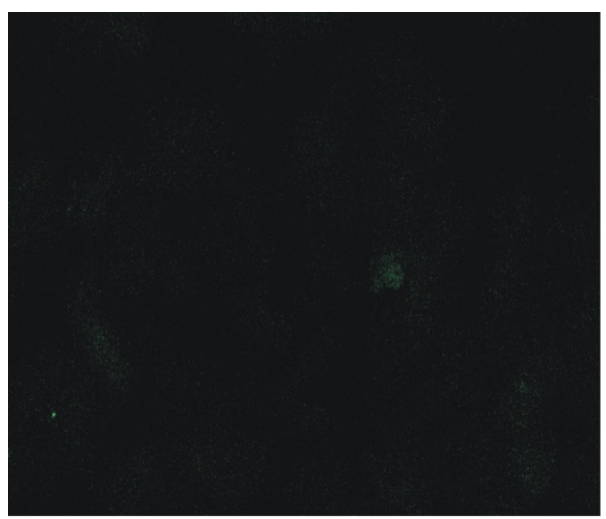

control

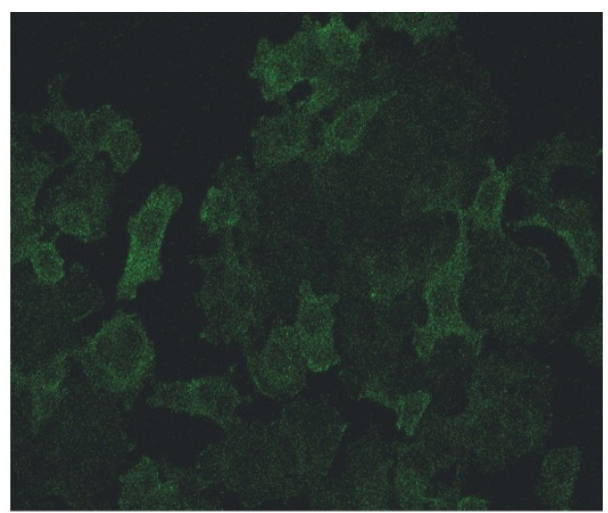

CRF 3h

\section{Phospho-FAK}

\section{Figure 6}

CRF induces the phosphorylation of FAK. MCF7 cells were treated with CRF (I0-8 M) or vehicle (control) for 3 hours, stained with phospho-FAK antibody and analyzed with confocal microscopy. Result is representative of three independent experiments.

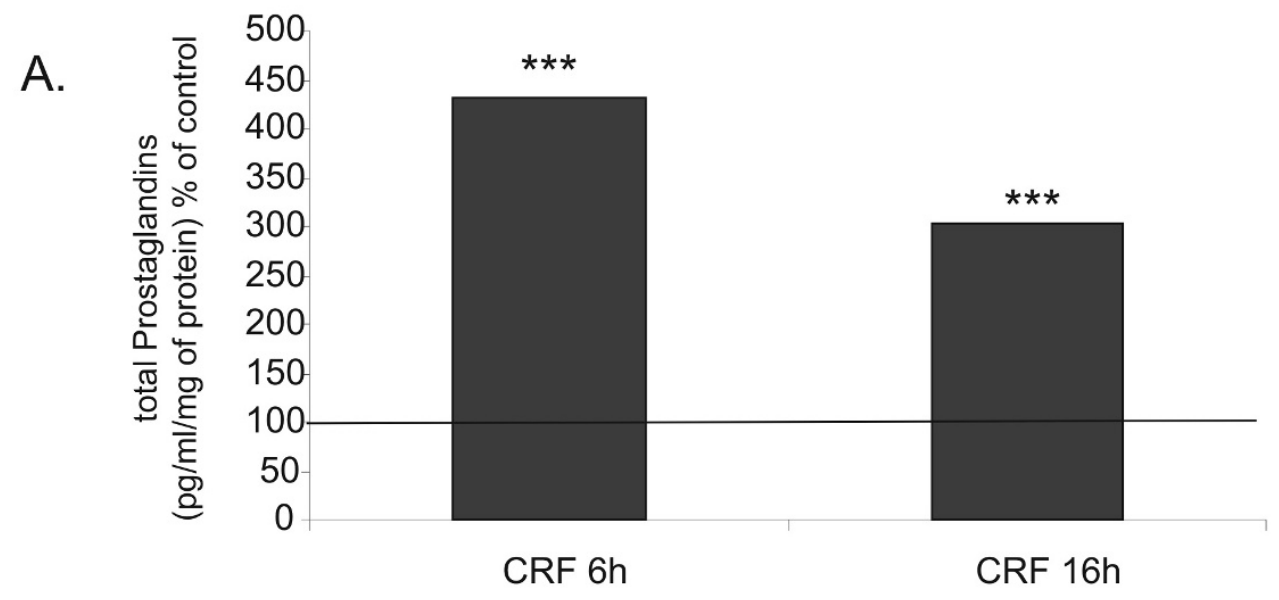

B.

\section{control CRF3h CRF6h CRF24h}

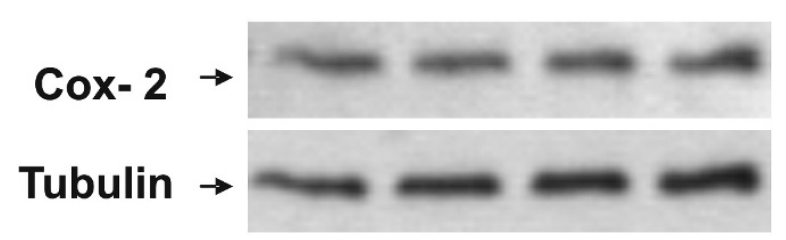

C.

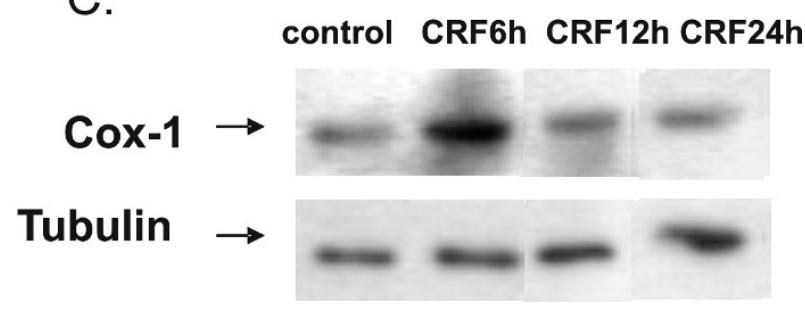

\section{Figure 7}

CRF induces the expression of Cox-I and the production of prostaglandins. A. MCF7 cells were treated with CRF $\left(I 0^{-8} \mathrm{M}\right)$ or vehicle (control) for 6 and 16 hours and total prostaglandin production in the supernatant was measured by ELISA; ${ }^{* * *} \mathrm{p}<0.00 \mathrm{I}$; Results represent the average of three independent experiments. B. MCF7 cells were treated with CRF (I0-8 M) for 3, 6 and 24 hours and Cox-2 was measured by western blot. C. MCF7 cells were treated with CRF (I0-8 M) for 6, I2 and 24 hours and Cox-I was measured by western blot. Results are representative of three independent experiments. 
Indeed, treatment with CRF increased the invasiveness of MCF7 cells through ECM. Invasiveness, through ECM was measured using a boyden chamber assay, in which cells were plated on an ECM coated surface. Hence, cells should not only obtain the capability of migration, they should also be able to destroy the ECM in order to penetrate tissue barriers and metastasize. MCF7 breast cancer cells obtain this capability by expressing matrix metalloproteinases [54].

Cyclooxygenase activation and prostaglandin production has also been associated with increase in metastasis $[47,55,56]$. Inhibition of Cox-2 is associated with decrease in tumor growth and invasiveness [56,57]. Cox1 , an otherwise constitutively expressed Cox isoform, is also upregulated in breast cancer and is associated with increased prostaglandins and metastatic potential $[56,58]$. The primary Cox isoform expressed in MCF7 cells is Cox-1 [59]. We, therefore, examined the production of prostaglandins in response to CRF in MCF7 cells. CRF induced prostaglandin production but it did not alter PGE2 levels. In contrast, CRF increased the levels of Cox1 suggesting that Cox-1-derived prostaglandins may mediate the effect of CRF on MCF7 cell invasiveness. Indeed, several reports have indicated that selective inhibition of Cox-1 results in inhibition of tumor growth and metastasis [56,58].

\section{Conclusion}

In conclusion, CRF appears to positively affect tumor growth by inhibiting apoptosis and promoting cell migration and invasiveness. Our results provide a potential link between stress and tumor growth, suggesting that CRF secreted from autonomic neurons innervating peripheral tissues [25] may contribute to breast cancer metastasis. Given recent findings for the anti-tumor properties of CRF2 agonists [30] and the lack of CRF2 expression on breast cancer cells one may suggest that inhibition of CRF1 and activation of CRF2 may successfully inhibit tumor growth.

\section{Abbreviations}

CRF: Corticotropin Releasing Factor; CRF1, CRF2: Corticotropin Releasing Factor receptor 1, or receptor 2; FAK: Focal Adhesion Kinase; UCN: Urocortin; COX: Cyclooxygenase; ECM: Extracellular Cell Matrix; PG: Prostaglandin; PGE2: Prostaglandin E2.

\section{Competing interests}

The authors declare that they have no competing interests.

\section{Authors' contributions}

AA participated in the molecular and cell biology studies and drafted the manuscript. ED participated in the immunofluorescence and confocal microscopy analyses and co-ordination of the study. MV participated in the analysis of CRF receptor expression, cell proliferation and apoptosis, data evaluation, co-ordination of the study and manuscript preparation. EK participated in the molecular and cell biology studies and data analysis. OR participated in the detection of CRF receptors. EA participated in the analysis of prostaglandin production and cyclooxygenase expression. CS and ANM participated in the design of the study and drafting of the manuscript. CT conceived of the study, participated in its design and drafted the manuscript. All authors read and approved the final manuscript.

\section{Acknowledgements}

This work was partly supported from the Association for International Cancer Research (AICR07-0072) to CT and from the Hellenic Secretariat for Research and Technology (IENEA 03EA372) to ANM.

\section{References}

I. Miao Y, Quinn TP: Alpha-melanocyte stimulating hormone peptide-targeted melanoma imaging. Front Biosci 2007, I 2:45 | 4-4524.

2. Gudermann T, Roelle S: Calcium-dependent growth regulation of small cell lung cancer cells by neuropeptides. Endocr Relat Cancer 2006, I 3:1069-1084.

3. Carraway RE, Plona AM: Involvement of neurotensin in cancer growth: evidence, mechanisms and development of diagnostic tools. Peptides 2006, 27:2445-2460.

4. Muller JM, Philippe M, Chevrier L, Heraud C, Alleaume C, Chadeneau C: The VIP-receptor system in neuroblastoma cells. Regul Pept 2006, I37:34-4I.

5. Graziani G, Tentori L, Portarena I, Barbarino M, Tringali G, Pozzoli G, Navarra P: CRH inhibits cell growth of human endometrial adenocarcinoma cells via CRH-receptor I-mediated activation of cAMP-PKA pathway. Endocrinology 2002, I43:807-8I3.

6. Sato H, Nagashima Y, Chrousos GP, Ichihashi M, Funasak Y: The expression of corticotropin-releasing hormone in melanoma. Pigment Cell Res 2002, I 5:98-103.

7. Funasaka Y, Sato H, Chakraborty AK, Ohashi A, Chrousos GP, Ichihashi $M$ : Expression of proopiomelanocortin, corticotropinreleasing hormone $(\mathrm{CRH})$, and $\mathrm{CRH}$ receptor in melanoma cells, nevus cells, and normal human melanocytes. J Investig Dermatol Symp Proc 1999, 4:105-109.

8. Minas V, Rolaki A, Kalantaridou SN, Sidiropoulos J, Mitrou S, Petsas G, Jeschke U, Paraskevaidis EA, Fountzilas G, Chrousos GP, Pavlidis $\mathrm{N}$, Makrigiannakis $\mathrm{A}$ : Intratumoral $\mathrm{CRH}$ modulates immunoescape of ovarian cancer cells through FasL regulation. $\mathrm{Br}$ J Cancer 2007, 97:637-645.

9. Boorse GC, Denver RJ: Widespread tissue distribution and diverse functions of corticotropin-releasing factor and related peptides. Gen Comp Endocrinol 2006, I46:9-18.

10. Dautzenberg FM, Hauger RL: The CRF peptide family and their receptors: yet more partners discovered. Trends Pharmacol Sci 2002, 23:71-77.

II. Brar BK, Jonassen AK, Stephanou A, Santilli G, Railson J, Knight RA, Yellon DM, Latchman DS: Urocortin protects against ischemic and reperfusion injury via a MAPK-dependent pathway. $\mathrm{J} \mathrm{Biol}$ Chem 2000, 275:8508-85।4.

12. Makrigiannakis A, Zoumakis E, Kalantaridou S, Mitsiades N, Margioris A, Chrousos GP, Gravanis A: Corticotropin-releasing hormone (CRH) and immunotolerance of the fetus. Biochem Pharmacol 2003, 65:917-921.

13. Chatzaki E, Charalampopoulos I, Leontidis C, Mouzas IA, Tzardi M, Tsatsanis C, Margioris AN, Gravanis A: Urocortin in human gastric mucosa: relationship to inflammatory activity. J Clin Endocrinol Metab 2003, 88:478-483.

14. Baigent SM: Peripheral corticotropin-releasing hormone and urocortin in the control of the immune response. Peptides 2001, 22:809-820. 
15. Agnello D, Bertini R, Sacco S, Meazza C, Villa P, Ghezzi P: Corticosteroid-independent inhibition of tumor necrosis factor production by the neuropeptide urocortin. Am J Physiol 1998, 275:E757-762

16. McEvoy AN, Bresnihan B, FitzGerald O, Murphy EP: Corticotropinreleasing hormone signaling in synovial tissue from patients with early inflammatory arthritis is mediated by the type I alpha corticotropin-releasing hormone receptor. Arthritis Rheum 200I, 44: I76I-1767.

17. Sashinami H, Kageyama K, Suda T, Nakane A: Urocortin 2 suppresses host resistance to Listeria monocytogenes infection via up-regulation of interleukin- I0. Endocrinology 2005, I46:5003-50II.

18. Tsatsanis C, Androulidaki A, Alissafi T, Charalampopoulos I, Dermitzaki E, Roger T, Gravanis A, Margioris AN: Corticotropin-releasing factor and the urocortins induce the expression of TLR4 in macrophages via activation of the transcription factors PU.I and AP-I. J Immunol 2006, I76:1869-1877.

19. Wang J, Li S: Corticotropin-releasing factor family and its receptors: tumor therapeutic targets? Biochem Biophys Res Commun 2007, 362:785-788.

20. Gutknecht E, Hauger RL, Linden I Van der, Vauquelin G, Dautzenberg FM: Expression, binding, and signaling properties of CRF2(a) receptors endogenously expressed in human retinoblastoma Y79 cells: passage-dependent regulation of functional receptors. I Neurochem 2008, I 04:926-936.

21. Dieterich KD, DeSouza EB: Functional corticotropin-releasing factor receptors in human neuroblastoma cells. Brain Res 1996, 733:113-118.

22. Schoeffter P, Feuerbach D, Bobirnac I, Gazi L, Longato R: Functional, endogenously expressed corticotropin-releasing factor receptor type I (CRFI) and CRFI receptor mRNA expression in human neuroblastoma SH-SY5Y cells. Fundam Clin Pharmacol 1999, I 3:484-489.

23. Graziani G, Tentori L, Muzi A, Vergati M, Tringali G, Pozzoli G, Navarra $P$ : Evidence that corticotropin-releasing hormone inhibits cell growth of human breast cancer cells via the activation of CRH-RI receptor subtype. Mol Cell Endocrinol 2007, 264:44-49.

24. Arbiser JL, Karalis K, Viswanathan A, Koike C, Anand-Apte B, Flynn E, Zetter B, Majzoub JA: Corticotropin-releasing hormone stimulates angiogenesis and epithelial tumor growth in the skin. J Invest Dermatol 1999, I | 3:838-842.

25. Bale TL, Vale WW: CRF and CRF receptors: role in stress responsivity and other behaviors. Annu Rev Pharmacol Toxicol 2004, 44:525-557.

26. Carlson KW, Nawy SS, Wei ET, Sadee W, Filov VA, Rezsova VV, Slominski A, Quillan JM: Inhibition of mouse melanoma cell proliferation by corticotropin-releasing hormone and its analogs. Anticancer Res 2001, 21:1173-1179.

27. Slominski AT, Roloff B, Zbytek B, Wei ET, Fechner K, Curry J, Wortsman J: Corticotropin releasing hormone and related peptides can act as bioregulatory factors in human keratinocytes. In Vitro Cell Dev Biol Anim 2000, 36:21 I-216.

28. Dermitzaki E, Tsatsanis C, Gravanis A, Margioris AN: Corticotropin-releasing hormone induces Fas ligand production and apoptosis in PCI 2 cells via activation of $\mathrm{p} 38$ mitogen-activated protein kinase. J Biol Chem 2002, 277: 12280-12287.

29. Radulovic M, Hippel C, Spiess J: Corticotropin-releasing factor (CRF) rapidly suppresses apoptosis by acting upstream of the activation of caspases. J Neurochem 2003, 84: $1074-1085$.

30. Hao Z, Huang Y, Cleman J, Jovin IS, Vale WW, Bale TL, Giordano FJ: Urocortin2 inhibits tumor growth via effects on vascularization and cell proliferation. Proc Natl Acad Sci USA 2008, 1 05:3939-3944.

31. Cao J, Papadopoulou N, Kempuraj D, Boucher WS, Sugimoto K, Cetrulo CL, Theoharides TC: Human mast cells express corticotropin-releasing hormone (CRH) receptors and CRH leads to selective secretion of vascular endothelial growth factor. J Immunol 2005, I 74:7665-7675.

32. Christoforidou AV, Papadaki HA, Margioris AN, Eliopoulos GD, Tsatsanis $C$ : Expression of the Tpl2/Cot oncogene in human T-cell neoplasias. Mol Cancer 2004, 3:34.

33. Kallergi G, Agelaki S, Markomanolaki H, Georgoulias V, Stournaras C: Activation of $\mathrm{FAK} / \mathrm{PI} 3 \mathrm{~K} / \mathrm{Racl}$ signaling controls actin reor- ganization and inhibits cell motility in human cancer cells. Cell Physiol Biochem 2007, 20:977-986.

34. Papakonstanti EA, Stournaras C: Actin cytoskeleton architecture and signaling in osmosensing. Methods Enzymol 2007, 428:227-240.

35. Gu JM, Lim SO, Park YM, Jung G: A novel splice variant of occludin deleted in exon 9 and its role in cell apoptosis and invasion. Febs J 2008, 275:3145-3I56.

36. Wang Z, Song W, Aboukameel A, Mohammad M, Wang G, Banerjee S, Kong D, Wang S, Sarkar FH, Mohammad RM: TW-37, a smallmolecule inhibitor of $\mathrm{Bcl}-2$, inhibits cell growth and invasion in pancreatic cancer. Int J Cancer 2008, I 23(4):958-66.

37. Kargiotis O, Chetty C, Gondi CS, Tsung AJ, Dinh DH, Gujrati M, Lakka SS, Kyritsis AP, Rao JS: Adenovirus-mediated transfer of siRNA against MMP-2 mRNA results in impaired invasion and tumor-induced angiogenesis, induces apoptosis in vitro and inhibits tumor growth in vivo in glioblastoma. Oncogene 2008, 27(35):4830-40.

38. Xiong $H$, Zhang ZG, Tian XQ, Sun DF, Liang QC, Zhang YJ, Lu R, Chen $Y X$, Fang JY: Inhibition of JAKI, 2/STAT3 signaling induces apoptosis, cell cycle arrest, and reduces tumor cell invasion in colorectal cancer cells. Neoplasia 2008, 10:287-297.

39. Machesky LM: Lamellipodia and filopodia in metastasis and invasion. FEBS Lett 2008, 582:2102-2III

40. Kallergi G, Tsapara A, Kampa M, Papakonstanti EA, Krasagakis K, Castanas $E$, Stournaras $C$ : Distinct signaling pathways regulate differential opioid effects on actin cytoskeleton in malignant MCF7 and nonmalignant MCFI2A human breast epithelial cells. Exp Cell Res 2003, 288:94-109.

4I. Papakonstanti EA, Stournaras C: Cell responses regulated by early reorganization of actin cytoskeleton. FEBS Lett 2008, 582:21 $20-2127$

42. Koukouritaki SB, Gravanis A, Stournaras C: Tyrosine phosphorylation of focal adhesion kinase and paxillin regulates the signaling mechanism of the rapid nongenomic action of dexamethasone on actin cytoskeleton. Mol Med 1999, 5:731-742.

43. Chen HC, Guan JL: Association of focal adhesion kinase with its potential substrate phosphatidylinositol 3-kinase. Proc Natl Acad Sci USA 1994, 9 I: 10148-10152.

44. Papakonstanti EA, Kampa M, Castanas E, Stournaras C: A rapid, nongenomic, signaling pathway regulates the actin reorganization induced by activation of membrane testosterone receptors. Mol Endocrinol 2003, 17:870-88I.

45. Hiraga T, Myoui A, Choi ME, Yoshikawa H, Yoneda T: Stimulation of cyclooxygenase-2 expression by bone-derived transforming growth factor-beta enhances bone metastases in breast cancer. Cancer Res 2006, 66:2067-2073.

46. Timoshenko AV, Xu G, Chakrabarti S, Lala PK, Chakraborty C: Role of prostaglandin E2 receptors in migration of murine and human breast cancer cells. Exp Cell Res 2003, 289:265-274.

47. Tsatsanis C, Androulidaki A, Venihaki M, Margioris AN: Signalling networks regulating cyclooxygenase-2. Int J Biochem Cell Biol 2006, 38: |654-I66I.

48. Basu GD, Liang WS, Stephan DA, Wegener LT, Conley CR, Pockaj $\mathrm{BA}$, Mukherjee P: A novel role for cyclooxygenase-2 in regulating vascular channel formation by human breast cancer cells. Breast Cancer Res 2006, 8:R69.

49. Olson MF, Sahai E: The actin cytoskeleton in cancer cell motility. Clin Exp Metastasis. 2009, 28(4):273-287.

50. Basson MD: An intracellular signal pathway that regulates cancer cell adhesion in response to extracellular forces. Cancer Res 2008, 68:2-4.

5I. Jones RJ, Brunton VG, Frame MC: Adhesion-linked kinases in cancer; emphasis on src, focal adhesion kinase and PI 3 kinase. Eur J Cancer 2000, 36:1595-1606.

52. Tremblay L, Hauck W, Aprikian AG, Begin LR, Chapdelaine A, Chevalier S: Focal adhesion kinase (pp I 25FAK) expression, activation and association with paxillin and p50CSK in human metastatic prostate carcinoma. Int / Cancer 1996, 68: I64-171.

53. Papadopoulou N, Charalampopoulos I, Alevizopoulos K, Gravanis A, Stournaras C: Rho/ROCK/actin signaling regulates membrane androgen receptor induced apoptosis in prostate cancer cells. Exp Cell Res 2008, 3 I4:3162-3174.

54. Milde-Langosch K, Roder H, Andritzky B, Aslan B, Hemminger G, Brinkmann A, Bamberger CM, Loning T, Bamberger AM: The role of 
the AP-I transcription factors C-Fos, FosB, Fra-I and Fra-2 in the invasion process of mammary carcinomas. Breast Cancer Res Treat 2004, 86: 139-152.

55. Surowiak P, Materna V, Matkowski R, Szczuraszek K, Kornafel J, Wojnar A, Pudelko M, Dietel M, Denkert C, Zabel M, Lage H: Relationship between the expression of cyclooxygenase 2 and MDR I/ P-glycoprotein in invasive breast cancers and their prognostic significance. Breast Cancer Res 2005, 7:R862-870.

56. Kundu N, Fulton AM: Selective cyclooxygenase (COX)-I or COX-2 inhibitors control metastatic disease in a murine model of breast cancer. Cancer Res 2002, 62:2343-2346.

57. Barnes NL, Warnberg F, Farnie G, White D, Jiang W, Anderson E, Bundred NJ: Cyclooxygenase-2 inhibition: effects on tumour growth, cell cycling and lymphangiogenesis in a xenograft model of breast cancer. BrJ Cancer 2007, 96:575-582.

58. Connolly EM, Harmey JH, O'Grady T, Foley D, Roche-Nagle G, Kay $E$, Bouchier-Hayes DJ: Cyclo-oxygenase inhibition reduces tumour growth and metastasis in an orthotopic model of breast cancer. Br J Cancer 2002, 87:231-237.

59. Liu $\mathrm{XH}$, Rose DP: Differential expression and regulation of cyclooxygenase- $I$ and -2 in two human breast cancer cell lines. Cancer Res 1996, 56:5 I25-5 I 27.

Publish with Biomed Central and every scientist can read your work free of charge

"BioMed Central will be the most significant development for disseminating the results of biomedical research in our lifetime."

Sir Paul Nurse, Cancer Research UK

Your research papers will be:

- available free of charge to the entire biomedical community

- peer reviewed and published immediately upon acceptance

- cited in PubMed and archived on PubMed Central

- yours - you keep the copyright

Submit your manuscript here:

http://www.biomedcentral.com/info/publishing_adv.asp
BioMedcentral 